\title{
Defects in Antigen-specific Immune Tolerance in Continuous B Cell Lines from Autoimmune Mice
}

\author{
Michael S. Brooks and Marlene Aldo-Benson \\ Department of Medicine, Division of Rheumatology, Indiana University School of Medicine, Indianapolis, Indiana 46223
}

\begin{abstract}
B cell hyperactivity and resistance to tolerance induction are well-recognized immunologic abnormalities associated with both human and murine models of systemic lupus erythematosus. Studies evaluating the role of $B$ cells in these defects have been complicated by the difficulties of consistently isolating large numbers of $B$ cells from $T$ cells and other host-derived regulatory factors. We have recently developed continuous cell lines of $B$ lymphocytes with a high degree of specificity for the antigen dinitrophenyl (DNP) from both New Zealand black times New Zealand white $F_{1}$ hybrid $\left(B W_{1}\right)$ and $B A L B / c$ mice, and we used them to study intrinsic $B$ cell defects in autoimmunity. We found that the kinetics of the immune response to the antigen DNP-Ficoll of both the BWF 1 and BALB/c B cell lines are not different. In addition, the $\mathrm{BWF}_{1}$ cell lines, like the $\mathrm{BALB} / \mathrm{c}$ cell lines and normal B cells, require nonspecific $T$ cell-derived factors as well as antigen to produce an immune response. Tolerance was tested in the BWF $B$ cells by preincubating them with DNPmurine IgG $_{2 n}$ (MGG), which can induce tolerance in BALB/c cell line lymphocytes. The BWF $B$ cell lines were resistant to tolerance induction by DNP-MGG and required 50-fold higher dose of DNP-MGG than BALB/c cell lines for suppression. They were also relatively resistant to tolerance with trinitrophenyl-d-glutamyl lysine. Thus, DNP-specific B cells from autoimmune mice have an inherent defect in tolerance induction.
\end{abstract}

\section{Introduction}

Our understanding of the immunologic defects associated with systemic lupus erythematosus has been greatly advanced by the use of several murine strains that develop an autoimmune disease very similar to systemic lupus erythematosus. Using these inbred strains of mice, several investigators have studied the phenomenon of immunologic tolerance in an attempt to pinpoint specific cellular defects associated with this autoimmune state (1-5). Most of these investigators have found that in general there is a relative resistance to tolerance induction in several strains of autoimmune mice. Several studies have attempted to determine whether this tolerance resistance is due to a defect in the B cell or in regulatory $\mathrm{T}$ cells. However, the results have been conflicting. For example, Goldings found a defect of tolerance in New Zea-

A preliminary report of this paper was published in abstract form (Arthritis Rheum. 285:26S).

Address reprint requests to Dr. Aldo-Benson, 541 Clinical Drive, Indianapolis, IN 46223.

Received for publication 4 February 1986 and in revised form 22 April 1986.

J. Clin. Invest.

(C) The American Society for Clinical Investigation, Inc.

0021-9738/86/09/0784/06 \$1.00

Volume 78, September 1986, 784-789 land black (NZB) ${ }^{1}$ B cells while Laskin et al. found a defect in $T$ cells $(2,3)$. Studies of specific cellular defects have been hindered by the difficulty in obtaining model systems in which large numbers of antigen-specific B cells can be isolated from other host cells and $\mathrm{T}$ cell-derived factors. Even in vitro studies in which $\mathrm{T}$ cell-depleted splenic lymphocytes were used cannot consistently avoid small amounts of $\mathrm{T}$ cell contamination (4). In addition, these splenic $B$ cells have matured in vivo under the influence of possibly abnormal host cells and $\mathrm{T}$ cell-derived factors, and this influence may last for several days after the cells are isolated in vitro (5). To overcome these difficulties we have developed continuous pure B cell lines from NZB times New Zealand white $(\mathrm{NZW}) \mathrm{F}_{1}$ hybrid mice $\left(\mathrm{BWF}_{1}\right)$ that have a significant proportion of cells that are specific for the hapten dinitrophenyl (DNP). These cells have been maintained in tissue culture for more than one year. These cell lines have no $\mathrm{T}$ cell or macrophage contamination and they are no different than previously described BALB/c cell lines (6) in terms of spontaneous $\left[{ }^{3} \mathrm{H}\right]$ thymidine and $\left[{ }^{3} \mathrm{H}\right]$ uridine uptake in the unstimulated state (7). These cells can be used as a model system for studying intrinsic B cell abnormalities in autoimmune mice.

The present studies make use of these DNP-specific B cell lines from both autoimmune $\mathrm{BWF}_{1}$ and normal $\mathrm{BALB} / \mathrm{c}$ mice to compare the antigen-specific immune response and tolerance induction between the $\mathrm{BWF}_{1}$ and $\mathrm{BALB} / \mathrm{c}$ cell lines. We found that the requirement of the $B W F_{1}$ cell lines for nonspecific $T$ cell factors in order to produce an immune response after stimulation with specific antigen was the same as that noted for BALB/c mice. We also found that the kinetics of the anti-DNP response to DNP-Ficoll was the same for normal and autoimmune cell lines. To investigate antigen-specific tolerance in the cells from autoimmune mice we used the system of tolerance induction in which the hapten DNP is bound to mouse $\operatorname{IgG}_{2 a}$ (DNP-MGG). DNP-MGG has been previously shown to induce tolerance in both normal splenic B lymphocytes and in cell line B lymphocytes from normal BALB/c mice $(8,9)$. We found that BWF $_{1} B$ cells from several pure $B$ cell lines were resistant to tolerance induction by both DNP-MGG and trinitrophenyl- $d$ glutamyl lysine (TNP-dGL). However, the resistance was not absolute, since higher doses of DNP-MGG or higher substitution ratios of TNP-dGL could be effective in tolerance induction. Thus we have demonstrated that $B$ cells from autoimmune $\mathrm{BWF}_{1}$ mice have an inherent defect that makes them relatively resistant to tolerance induction.

\section{Methods}

Animals. 8-wk-old female BALB/c mice were used for the propagation of the plasmacytoma RPC5. 3-6-wk-old female Sprague-Dawley rats

1. Abbreviations used in this paper: $\mathrm{BWF}_{1}, \mathrm{NZB}$ times $\mathrm{NZW} \mathrm{F}_{1}$ hybrid mice; dGL, $d$-glutamyl lysine; DME, Dulbecco's modified Eagle's medium; DNP, dinitrophenyl; MGG, murine $\mathrm{IgG}_{2 \mathrm{a}}$; NZB, New Zealand black; NZW, New Zealand white; PMA, phorbol myristate acetate, PFC, plaque-forming cell; TNP, trinitrophenyl. 
were used as a source of irradiated normal thymus filler cells. 8-14-wkold female C57BL/6 mice were used for the passage and maintenance of the EL-4 lymphoma cell line. All of these animals were obtained from

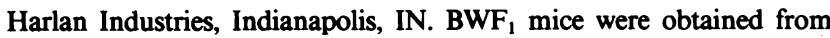
The Jackson Laboratory, Bar Harbor, ME, and used to develop the cell lines.

$T$ cell-derived growth and differentiation factors. EL-4 lymphoma cells were passaged by intraperitoneal injection into $\mathrm{C} 57 \mathrm{BL} / 6$ mice. The cells were harvested from the peritoneum. $2 \times 10^{6} / \mathrm{ml}$ sterile EL-4 cells were then grown in culture for $24 \mathrm{~h}$ in serum-free RPMI medium supplemented with penicillin, streptomycin, and $10 \mathrm{ng} / \mathrm{ml}$ of phorbol myristate acetate (PMA), washed thoroughly to remove the PMA, and placed back in RPMI medium. The supernatant was collected after $48 \mathrm{~h}$ of further growth without PMA and stored in aliquots at $-70^{\circ} \mathrm{C}$. This EL4 supernatant has been previously shown to be required for both continuous growth of the cell lines and for an immune response in DNPFicoll-stimulated cell line lymphocytes $(6,10)$.

DNP-specific B cell lines. B lymphocyte lines from normal BALB/c 8-12-wk-old female mice were isolated and propagated as previously described (6). The characteristics of these BALB/c cell lines have been described elsewhere. (11) Briefly, the cell lines are nonmalignant and not transformed and are propogated in the absence of antigen. They have resting B cells as well as some B cells in the activated state, and thus are similar to splenic B cells, as described by Thompson et al. $(11,12)$. Similar continuous $B$ cell lines were isolated from autoimmune BWF $_{1}$ mice and propagated as described for BALB/c mice (7) (manuscript in preparation). Briefly, splenic lymphocytes from 8-wk-old female $\mathrm{BWF}_{1}$ mice were enriched for DNP-specific B cells by the method of Haas and Layton (13). The enriched cells were cloned in soft agar by a modification of the method of Pillai and Scott (14). After $24 \mathrm{~h}$ incubation the cells were layered over with complete Dulbecco's modified Eagle's medium (DME) with $20 \%$ EL-4 supernatant. As the colonies became macroscopic they were picked from the agar with the aid of a dissecting microscope and placed in individual wells of a 96-well culture plate (Falcon Labware, Div. of Becton-Dickinson \& Co., Oxnard, CA). When cells had grown to confluency they were transferred to 24-cm tissue culture flasks.

These cells are pure B cell lines with no macrophage or $\mathrm{T}$ cell contamination $(6,7)$ (manuscript in preparation). The cell lines are maintained in DME supplemented with $100 \mathrm{U} / \mathrm{ml}$ penicillin, $100 \mu \mathrm{g} / \mathrm{ml}$ streptomycin, $5 \times 10^{-5} \mathrm{M}$ 2-mercaptoethanol, $0.1 \mathrm{mM}$ nonessential amino acids, $100 \mathrm{mM}$ L-glutamine, and $10 \%$ fetal calf serum (HyClone Sterile Systems, Inc., Logan, UT). 20\% EL-4 supernatant was required for the continued growth of these cell lines in culture. The medium was changed twice weekly and the cultures split when they became confluent. There is no antigen or lipopolysaccharide present in the medium.

Antigen stimulation of cell line lymphocytes. $10^{5}$ cell line lymphocytes from either the $\mathrm{BALB} / \mathrm{c}$ or the $\mathrm{BWF}_{1}$ cell lines were placed in individual wells of a 96-well microculture plate. DNP-Ficoll $(20 \mathrm{ng} / \mathrm{ml})$ was added to each well of the antigen-stimulated groups and the volume of the well was brought up to $250 \mu \mathrm{l}$ using complete DME. Except where indicated in results, $20 \%$ EL-4 supernatant and $10^{5}$ freshly obtained normal rat thymus cells that had been irradiated with 2,000 rad 1-2 $\mathrm{h}$ before culture were added to each well. Background response was determined by culturing line cells with EL-4 supernatant and filler cells without antigen. After $4 \mathrm{~d}$ in culture the cells were washed thoroughly to remove the DNP-Ficoll and placed back in culture overnight with $250 \mu \mathrm{l}$ complete DME. The following day the number of antibody-forming cells was assayed by the Cunningham slide modification of the Jerne plaque-forming cell (PFC) assay using trinitrophenyl (TNP)-coated sheep red blood cells as target cells (15). Irradiated thymus cells alone were also cultured with antigen and produced no significant PFC.

Cell line kinetics. $10^{5}$ cell line lymphocytes were placed in individual wells of a 96-well microculture plate with $20 \mathrm{ng} / \mathrm{ml} \mathrm{DNP-Ficoll,} 10^{5}$ irradiated rat thymus filler cells, and $250 \mu \mathrm{l}$ DME complete medium containing 20\% EL-4 supernatant. At various times after the initiation of these cultures, sample wells were washed thoroughly to remove the DNP-Ficoll and a PFC assay was performed using Cunningham slides as previously described. The response of the $B A L B / c$ and $B W F_{1}$ cell line lymphocytes to DNP-Ficoll at various times were compared with each other and to normal splenic lymphocytes from BALB/c mice.

Tolerance induction. $10^{3}$ cell line lymphocytes were placed in individual wells of a 96-well microculture plate with varying doses of DNPMGG or TNP-dGL. The total volume of each well was $250 \mu$ l. After 48 h of preincubation with DNP-MGG, the cell line lymphocytes were washed three times to remove all tolerogen and placed back in culture with $20 \mathrm{ng} / \mathrm{ml}$ of the antigen DNP-Ficoll plus $10^{5}$ rat thymus filler cells irradiated with $2,000 \mathrm{rad}$. After $4 \mathrm{~d}$ in culture the antibody-forming cells were assayed as noted above. $20 \%$ EL-4 supernatant was also present during preincubation with tolerogen. Cultures preincubated in medium without tolerogen and then cultured with DNP-Ficoll were used as immune controls. Cultures incubated without either tolerogen or DNPFicoll were used as background controls.

In some experiments cells were grown for $30 \mathrm{~d}$ in the presence of DNP-MGG. Controls were treated in the same fashion but did not have DNP-MGG in the medium. At the end of this $30-d$ period the cells were washed free of tolerogen and placed back in culture. At varying numbers of days after removal of DNP-MGG, aliquots of cells from control or DNP-MGG groups were cultured with antigen in the presence of filler cells and EL-4 supernatant, and the PFC response assayed $5 \mathrm{~d}$ later.

Hapten-protein conjugates. 2,4-Dinitrobenzene sulfonic acid was twice recrystalized according to the method of Eisen and bound to murine $\mathrm{IgG}_{2 \mathrm{a}}$ as previously described (16). Murine $\mathrm{IgG}_{2 \mathrm{a}}$ was separated from the ascites of mice bearing the plasmacytoma RPC5 by starch block electrophoresis as previously described (17). DNP-Ficoll was obtained from Biosearch, San Rafael, CA. TNP 7 dGL was the generous gift of Dr. Eliot Goldings (University of Texas Health Science Center at Dallas, TX). $\mathrm{TNP}_{27} \mathrm{dGL}$ and $\mathrm{TNP}_{116}$ dGL were made by conjugating TNP to the dGL polymer by the method of Goldings and Mosier (18).

Viability assay. $10^{5}$ cell line lymphocytes were incubated for $24 \mathrm{~h}$ in DME with $20 \%$ EL -4 growth factors and varying concentrations of DNPMGG. The cells were then tested for viability by trypan blue dye exclusion.

Statistics. Values expressed are the means \pm standard errors of 3-4 separate cultures. Each experiment was performed 2-3 times to document reproducibility of data. In most cases only data from one representative experiment is shown. Groups were statistically compared using a onetailed Student's $t$ test.

\section{Results}

Previous results in our laboratory have shown that the nonautoimmune BALB/c cell lines require filler cells and nonspecific $T$ cell-derived factors to produce an immune response upon stimulation with DNP-Ficoll (11). This requirement for soluble $\mathrm{T}$ cell-derived factors for antibody production to occur after stimulation with $\mathrm{T}$-independent antigen is similar to that found in normal B cells (18-20). The possibility was raised that such a requirement may be absent in the $\mathrm{BWF}_{1}$ cell lines, since these mice have an increased number of $B$ cells spontaneously secreting antibody and their $B$ cells have been shown to be hyperactive in vivo (21). To test this we cultured $\mathrm{BWF}_{1}$ cell line lymphocytes with $20 \mathrm{ng} / \mathrm{ml}$ of DNP-Ficoll both with and without EL-4 supernatant and irradiated normal rat thymus filler cells. The BWF $B$ cell lines show no increase over background in antibodyforming cells after stimulation with DNP-Ficoll in the absence of EL-4 supernatant and filler cells (Fig. 1). However, a significant immune response occurs when these cell line lymphocytes are stimulated with DNP-Ficoll in the presence of these factors $(P$ $<0.05$ ).

The kinetics of the immune response in these cell line lymphocytes was measured at various times after stimulation of the cells with DNP-Ficoll in the presence of EL-4 supernatant and filler cells. The peak response of the $\mathrm{BWF}_{1}$ cells occurs at 4-5 d after antigen-specific activation, and there is a return to background levels of antibody-forming cells by $8 \mathrm{~d}$ after stimulation 
CELL LINE BWF, 37

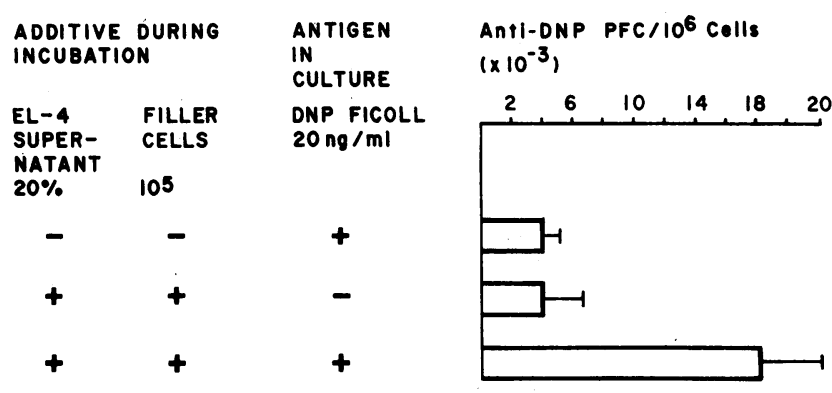

Figure 1. Requirements for an immune response in $\mathrm{BWF}_{1} \mathrm{~B}$ lymphocyte lines. Cell line lymphocytes were cultured for $4 \mathrm{~d}$ with either 20 $\mathrm{ng} / \mathrm{ml}$ DNP-Ficoll, with filler cells and EL-4 supernatant alone, or with all three. Only the cell line cultures that contained all three constituents demonstrated a significant PFC response $(P<0.05)$.

(Fig. 2, $A$ and $B$ ). This response is similar to that found for the BALB/c cell line lymphocytes and is also similar to that found in freshly obtained splenic lymphocytes from BALB/c mice.

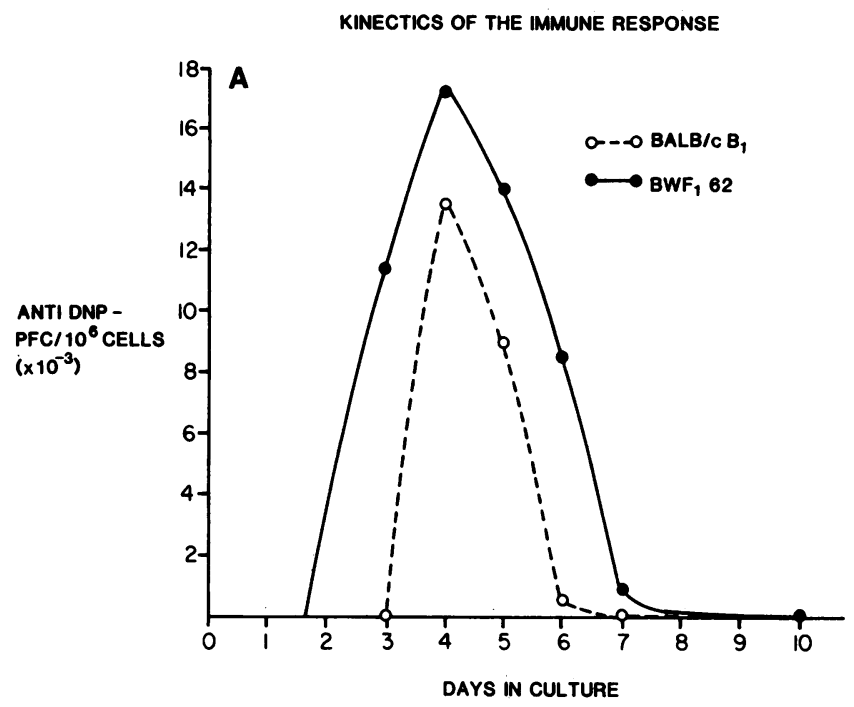

KINETICS OF IMMUNE RESPONSE

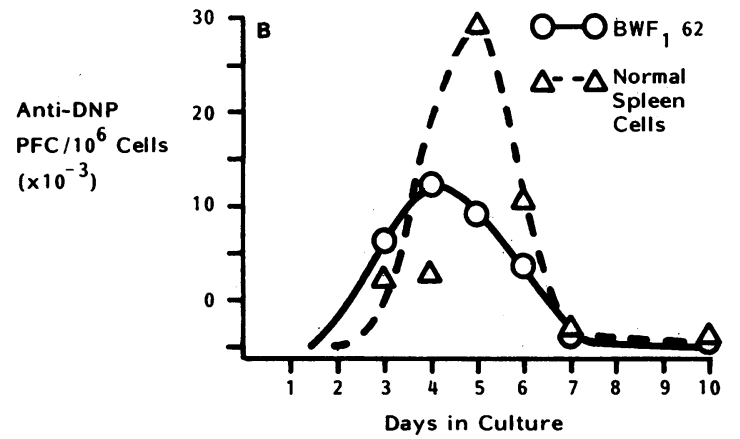

Figure 2. Kinetics of immune response in $\mathrm{BWF}_{1}$ cell lines compared with BALB/c cell lines and normal spleen cells. $(A)$ Both BALB/c and $\mathrm{BWF}_{1}$ cell line lymphocytes were cultured with antigen, filler cells, and EL-4 supernatant. The PFC response was assayed on varying days after the start of culture. The PFC response to DNP-Ficoll antigen peaked on day 4 for both $B A L B / c$ and $B_{1} F_{1}$ cell line lymphocytes. $(B)$ The kinetics of $\mathrm{BWF}_{1}$ cell line is compared with that of normal spleen cells. The PFC response of BWF $_{1}$ cell line cells again peaked on day 4, which is one day earlier than normal spleen cells from BALB/c mice peaked.
To study the phenomena of antigen-specific tolerance we used DNP-MGG as a tolerogen because, in previous studies, we have shown that preincubation of BALB/c cell lines for $48 \mathrm{~h}$ with DNP-MGG renders them tolerant to further stimulation with DNP-Ficoll (9). This tolerance in BALB/c cell line lymphocytes is antigen specific, occurs with or without nonspecific $\mathrm{T}$ cell factors present in the preincubation period, and occurs at a concentration of $10-200 \mu \mathrm{g} / \mathrm{ml}$ of DNP-MGG (9). To test whether there was a tolerance defect inherent in the $\mathrm{BWF}_{1} \mathrm{~B}$ cells, cells from both the $\mathrm{BALB} / \mathrm{c}$ and the $\mathrm{BWF}_{1}$ cell lines were preincubated for $48 \mathrm{~h}$ with $200 \mu \mathrm{g} / \mathrm{ml}$ DNP-MGG, washed free of tolerogen and then cultured with DNP-Ficoll, filler cells and EL-4 supernatant for $4 \mathrm{~d}$, washed, and assayed for PFC. Appropriate immune and background controls were set up as described for each cell line. There was a statistically significant suppression $(P<0.05)$ of the BALB/c cells preincubated with DNP-MGG when compared with the immune controls (Fig. 3). However, BWF $_{1}$ cell lines preincubated with DNP-MGG were not significantly suppressed compared with control $\mathrm{BWF}_{1}$ cells. Similar experiments with three other BWF $_{1}$ cell lines and three BALB/ $\mathrm{c}$ lines gave identical results (data not shown).

Goldings has shown that in B lymphocytes isolated from spleens of $\mathrm{BWF}_{1}$ mice, resistance to tolerance induction is partially dependent upon the epitope density of the antigen carrier complex (3). To test whether a similar dependence on the epitope density of DNP-MGG was involved in the resistance to tolerance seen here, the experiments were repeated using $\mathrm{DNP}_{26}$ MGG and $\mathrm{DNP}_{12} \mathrm{MGG}$. Tolerance in the $\mathrm{BWF}_{1}$ cells was not induced at either epitope density (Fig. 4). Since it is known that DNPMGG at epitope densities above 30 will not induce tolerance in nonautoimmune lymphocytes, we did not test DNP-MGG with a very high substitution ratio (22).

The $\mathrm{BWF}_{1}$ cell line lymphocytes were preincubated with DNP-MGG at various concentrations ranging from 200 to 1,000 $\mu \mathrm{g} / \mathrm{ml}$. As before, the $\mathrm{BWF}_{1}$ cells preincubated with $200 \mu \mathrm{g} / \mathrm{ml}$ DNP-MGG showed no statistically significant difference in their response to stimulation with DNP-Ficoll. However, there was a significant difference in the PFC response of those cells preincubated with DNP-MGG at concentrations of 500 and 1,000 $\mu \mathrm{g} / \mathrm{ml}$ (Fig. 5). A cytotoxicity assay using trypan blue exclusion showed that incubation of the cells with $500 \mu \mathrm{g} / \mathrm{ml}$ of DNPMGG produced no significant cell death, but a mild degree of cytotoxicity was found in some cell lines when tested with 1,000

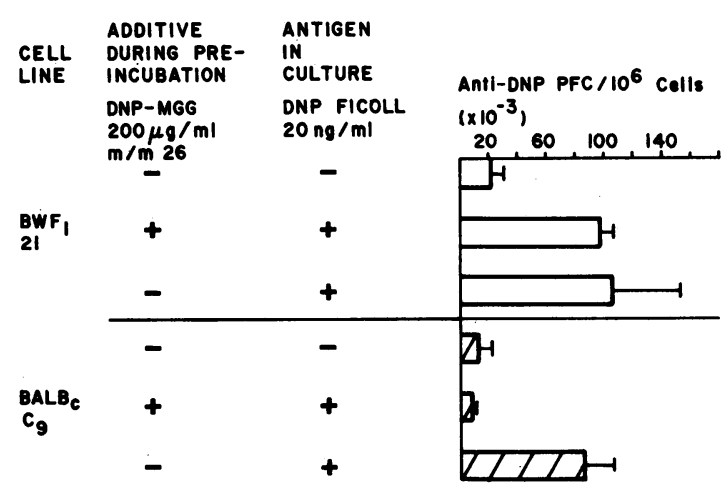

Figure 3. $\mathrm{BWF}_{1}$ cell line lymphocytes are resistant to tolerance induction by DNP-MGG. A 48-h preincubation of BALB/c cell line cells with DNP-MGG before culture with antigen DNP-Ficoll suppressed their PFC response compared with their control $(P<0.01)$. Similar treatment of $\mathrm{BWF}_{1}$ cell line did not suppress the anti-DNP response $(P>0.10)$. 
CELL LINE BWF 29

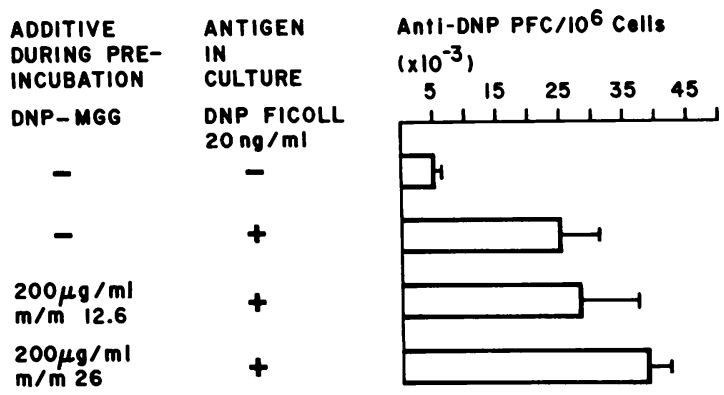

Figure 4. Effect of varying the hapten carrier ratio on tolerance induction by DNP-MGG in $\mathrm{BWF}_{1}$ cell lines. A 48-h preincubation of $\mathrm{BWF}_{1}$ cell line lymphocytes with either moderate or highly substituted DNPMGG conjugates was followed by culture with antigen. Neither $\mathrm{DNP}_{12.6} \mathrm{MGG}$ or $\mathrm{DNP}_{26} \mathrm{MGG}$ suppressed the immune response of $\mathrm{BWF}_{1} 29$ cell line.

$\mu \mathrm{g} / \mathrm{ml}$ DNP-MGG. Thus, at least $500 \mu \mathrm{g} / \mathrm{ml}$ DNP-MGG is needed to induce tolerance in $\mathrm{BWF}_{1} \mathrm{~B}$ cells, which indicates that $\mathrm{BWF}_{1} \mathrm{~B}$ cell lines have a 50-fold difference in sensitivity to tolerance induction with DNP-MGG when compared with the BALB/c cell lines.

Similar studies were done using the tolerogen TNP-dGL, which induces B cell tolerance without affecting Fc receptors. TNP-dGL $(100 \mu \mathrm{g} / \mathrm{ml})$ of varying epitope densities was used in each 48-h preincubation. The results (Fig. 6) show that TNP dGL did not induce tolerance in either $B A L B / c$ or $B W F_{1}$ cell lines. $\mathrm{TNP}_{27} \mathrm{dGL}$ induced tolerance in nonautoimmune $\mathrm{BALB} /$ c cell lines $(P<0.05)$ but not in the $\mathrm{BWF}_{1}$ cell lines, while $\mathrm{TNP}_{133} \mathrm{dGL}$ induced tolerance in both $\mathrm{BWF}_{1}$ and $\mathrm{BALB} / \mathrm{c}$ cell line lymphocytes.

We have previously shown that BALB/c cell lines can grow in the presence of DNP-MGG, and become tolerant. This tolerance has many characteristics that are predicted for the theoretical clonal anergy $(23,24)$. Thus, we tested whether B cell lines from autoimmune mice can grow in the presence of DNPMGG, and whether they become tolerant. Several cell lines were propagated in the presence of $200 \mu \mathrm{g} / \mathrm{ml} \mathrm{DNP-MGG} \mathrm{and} \mathrm{tested}$ for tolerance as described in Methods. The BWF 1 and BALB/c cell lines were tolerant at the end of $30 \mathrm{~d}$ (Fig. 7). Like the $\mathrm{BALB} / \mathrm{c}$ cell lines, the $\mathrm{BWF}_{1}$ cell lines lost tolerance soon after removal of DNP-MGG.

\section{CELL LINE BWF, 29}

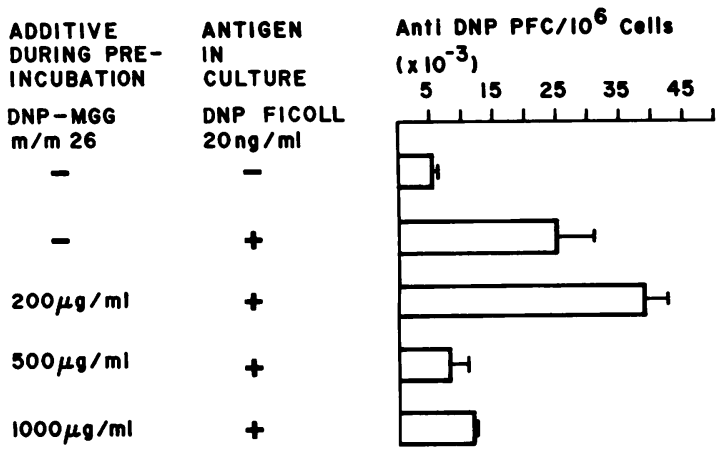

Figure 5. Effect of dose of DNP-MGG on tolerance induction. BWF cell line lymphocytes were preincubated with varying doses of DNPMGG, and then cultured with antigen. While $200 \mu \mathrm{g}$ of DNP-MGG did not suppress the PFC response of BWF $29(P>0.05)$, both 500 $\mu \mathrm{g} / \mathrm{ml}$ and $1 \mathrm{mg} / \mathrm{ml}$ inhibit the anti-DNP response $(P<0.05)$.

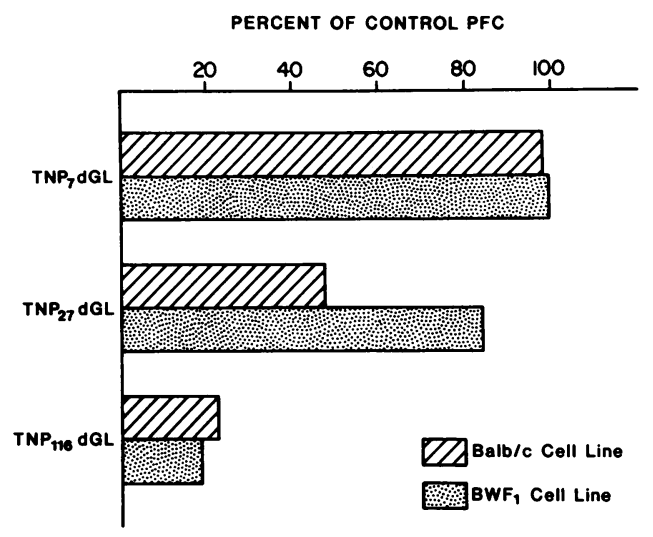

Figure 6. Effect of varying the hapten carrier ratio on the induction of tolerance by TNP-dGL in BALB/c and BWF, cell lines. Cell line lymphocytes were preincubated with TNP-dGL of varying substitution ratios for $48 \mathrm{~h}$, washed, and their anti-TNP response compared with the response of controls incubated with DNP-Ficoll alone. The results are expressed as percent of the control (DNP-Ficoll) response. TNP 27 dGL suppressed the response of BALB/c cells $(P<0.05)$ but not BWF cells $(P>0.10)$. TNP ${ }_{116}$ dGL suppressed both cell lines $(P<0.01)$.

\section{Discussion}

The availability of pure B cell lines that have been outside of the host regulatory influence for a period of time allows us to explore possible defects of $B$ cell response that may be intrinsic to the B cell itself. Although these B cell lines are not entirely "normal" due to their prolonged in vitro growth, they are nonmalignant and have many characteristics that are similar to normal splenic $\mathrm{B}$ cells (11). Since the $\mathrm{BWF}_{1}$ cell lines are being compared with nonautoimmune BALB/c cell lines, any abnormalities of the cells that could be due to prolonged in vitro growth would be controlled, since they should also exist in BALB/c lines. Tolerance induction in these cell lines is similar to that seen in splenic B cells in vitro: it is antigen specific, dose dependent, and not associated with cell death (11). Thus, this is a suitable model for the study of the tolerance defect in the BWF B cell.

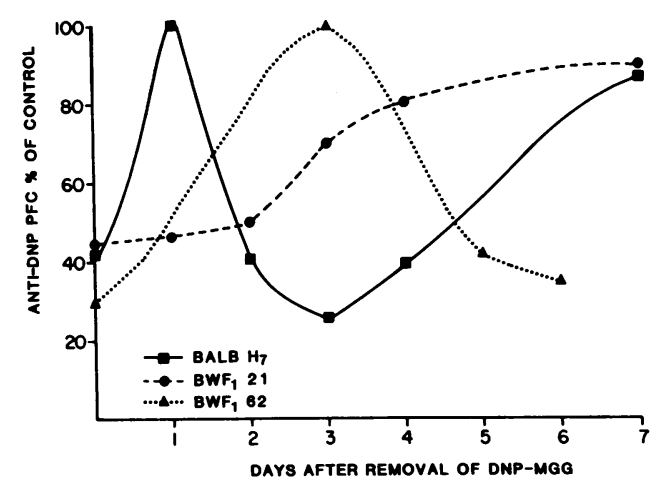

Figure 7. Propagation of $\mathrm{BWF}_{1}$ cell lines in the presence of DNPMGG for $30 \mathrm{~d}$ suppresses their response to DNP-Ficoll. Both BWF and BALB/c cell line cells were propagated in the presence of $200 \mu \mathrm{g} /$ $\mathrm{ml}$ DNP-MGG for $30 \mathrm{~d}$. The cells were then washed free of DNPMGG and placed back in culture. At varying times after removal of DNP-MGG, some of the cells were stimulated with antigen and their PFC response compared with controls. BWF cell lines were significantly suppressed on day zero but lost tolerance soon after removal of DNP-MGG. This is similar to the response of BALB/c cell line lymphocytes. 
These studies indicate that the $\mathrm{BWF}_{1} \mathrm{~B}$ cell line lymphocytes are no different than the normal BALB/c cell lines or normal spleen cells in the kinetics of the immune response produced by antigen-specific stimulation with DNP-Ficoll. These BWF $_{1}$ cell lines are also similar to BALB/c cells in their requirement for filler cells and nonspecific $\mathrm{T}$ cell-derived factors to produce an immune response upon antigen stimulation. These studies do not address the question of whether autoimmune B cell lines produce more antibody or greater numbers of PFC after stimulation, nor do they rule out the possibility that the cells may require significantly lower concentrations of $T$ cell-derived factors to initiate and sustain an immune response. These questions are being addressed in other studies. However, we have demonstrated that $\mathrm{B}$ cells from $\mathrm{BWF}_{1}$ mice do have a resistance to tolerance that is intrinsic and not dependent on $\mathrm{T}$ cells.

Our studies do not rule out the possibility that there is a concomitant defect in the $T$ cells themselves or in the $T$ cellderived growth factors that may also play a role in the abnormal antigen-specific tolerance seen in $\mathrm{BWF}_{1}$ mice. Nor can these experiments be extrapolated to tolerance of nucleoside or DNA antigens or to other strains of autoimmune mice. Most of the studies showing tolerance defects have used heterologous antigens, and indeed this study also uses the heterologous determinant DNP. However, Lewis et al. was able to induce tolerance to the self antigen, nucleosides, in $\mathrm{BWF}_{1}$ mice (25). Thus, these studies do not address mechanisms of self-tolerance directly. However, we now have the ability using these same methods to study antigen-specific tolerance in other mouse strains, and with self-antigenic determinants that may be more pertinent to the autoimmune process.

The resistance to tolerance in the $\mathrm{BWF}_{1} \mathrm{~B}$ cell is not absolute, but is due to a decrease in sensitivity of the cell to tolerance induction. Tolerance to DNP-MGG requires 50 times more tolerogen than needed for BALB/c B cells. TNP-dGL requires fivefold increase in the density of hapten on carrier. Goldings has previously shown that the tolerance defect in NZB mice in vivo is not seen with high hapten carrier ratios (3). Thus, these in vitro studies are in agreement with previous in vivo data. The exact defect responsible for the resistance to tolerance induction seen in the $\mathrm{BWF}_{1}$ cell lines is not yet clearly understood. There are a number of possible explanations for this. It is unlikely that Fc receptors play a role, since there is also resistance to tolerance with TNP-dGL. Perhaps there are fewer receptors by which the DNP-MGG initiates tolerance. Alternatively, the receptor affinity for DNP-MGG may be lower than that on the normal B cells. That higher doses of DNP-MGG and higher epitope density of TNP-dGL can induce tolerance is compatible with these possibilities. However, it may also be possible that the receptors themselves are normal, but the biochemical events that follow receptor tolerogen interaction are abnormal. It is obvious that further studies are required to determine what changes occur in these cells once they are exposed to tolerogen and what differences there are in these changes between the B cell lines from normal and autoimmune mice.

There is a great deal of evidence that propagating the B cell lines in the presence of DNP-MGG is a model of clonal anergy $(23,24)$. B cells grown in the presence of DNP-MGG grow at the same rate as controls and continue to develop and express surface receptors to the same extent as controls, but they become unresponsive to antigen. That $\mathrm{BWF}_{1}$ cells grown in DNP-MGG also become unresponsive to the same extent as controls suggests that immature B cells from this strain are not as resistant to tolerance as the mature B cells. An alternative explanation is that longer exposure of mature cells to the tolerogen may allow tolerance induction. These alternatives are being explored. However, our findings of normal tolerance induction in immature $\mathrm{BWF}_{1} \mathrm{~B}$ cells and defects in tolerance induction in mature $B$ cells are compatible with the course of events in the BWF mouse, in which the animal is tolerant to self after birth but acquires autoimmunity as it gets older.

\section{Acknowledgments}

The authors wish to thank Linda Pratt for her expert technical assistance, and Donna Faulkner for her assistance in preparing the manuscript.

This work was supported by U. S. Public Health Service grants AI-21066, AM-7448, and AM-20582, by an Arthritis Foundation Center grant, and by a grant from the Grace M. Showalter Trust.

\section{References}

1. Hang, L., S. Izui, J. H. Slack, and F. J. Dixon. 1981. The cellular basis for resistance to induction of tolerance in BXSB SLE male mice. J. Immunol. 129:787-789.

2. Laskin, C. A., J. D. Tauroy, P. A. Smothers, and A. D. Steinberg. 1981. Studies of defective tolerance induction in murine lupus. J. Immunol. 127:1743-1747.

3. Goldings, E. A. 1983. Defective B cell tolerance induction in New Zealand black mice: macrophage independence and comparison with other autoimmune strains. J. Immunol. 131:2630-2634.

4. Prud'Homme, G. J., R. S. Balderas, F. J. Dixon, and A. N. Theofilopoulos. 1983. B cell dependence on and response to accessory signals in murine lupus. J. Exp. Med. 157:1815-1820.

5. Theofilopoulos, A. N., and F. J. Dixon. 1981. Etiopathogenesis of murine SLE. Immunol. Rev. 55:179-216.

6. Aldo-Benson, M. A., and L. M. Scheiderer. 1983. Long-term growth of lines of murine dinitrophenyl-specific B lymphocytes in vitro. J. Exp. Med. 157:342-347.

7. Brooks, M., and M. A. Aldo-Benson. 1985. Studies of autoimmune B cell defects in continuous DNP specific B cell lines. Arthritis Rheum. 285:265. (Abstr.)

8. Aldo-Benson, M. A. 1979. Antigen-specific suppressor cells in hapten-specific carrier-determined tolerance. Eur. J. Immunol. 9:214219.

9. Aldo-Benson, M. A., and L. M. Scheiderer. 1985. Tolerance and immunity in antigen-specific B-lymphocyte lines: early receptor binding of either antigen or tolerogen initiates an immune response. Cell. Immunol. 94:312-325.

10. Scheiderer, L. M., and M. A. Aldo-Benson. 1984. Investigation of clonal anergy in cell lines of DNP-specific normal B lymphocytes. Fed. Proc. 43:1737. (Abstr.)

11. Aldo-Benson, M. A., L. M. Scheiderer, and F. E. Dwulet. 1986. DNP-specific continuous B cell lines as a model system for studying B cell activation and tolerance. Eur. J. Immunol. 16:69-74.

12. Thompson, C. G., I. Scher, M. E. Schaefer, T. Lindsten, F. D. Finkelman, and J. Mond. 1984. Size dependent B lymphocyte populations: relationship of cell volume to surface phenotype, cell cycle, proliferative response, and requirements for antibody production to TNPFicoll and TNP-BA. J. Immunol. 133:2333-2342.

13. Haas, W., and J. E. Layton. 1975. Separation of antigen-specific lymphocytes. I. Enrichment of antigen binding cells. J. Exp. Med. 141: 1004-1013.

14. Pillai, P. S., and D. W. Scott. 1981. Hapten-specific murine colonyforming B cells: in vitro response of colonies to fluoresceinated thymus independent antigens. J. Immunol. 126:1883-1886.

15. Cunningham, A. J., and A. Szenberg. 1968. Further improvements 
in the plaque technique for detecting single antibody-forming cells. Immunology. 14:599-608.

16. Eisen, H. N. 1964. Preparation of purified anti-2,4-dinitrophenyl antibodies. Methods Med. Res. 10:94-101.

17. Aldo-Benson, M. A., and A. M. Watanabe. 1981. The effects of cyclic nucleotides on tolerance induction by dinitrophenyl-isologous immunoglobulin G. Immunopharmacology. 3:299-308.

18. Goldings, E. A., and D. E. Mosier. 1979. Ontogeny of susceptibility of mouse splenic B cells to tolerance induction in vitro by TNP-D-GL. Eur. J. Immunol. 9:76-80.

19. DeFranco, A. L., E. S. Ravache, R. Asofsky, and W. E. Paul. 1982. Frequency of $B$ lymphocytes responsive to anti-immunoglobulin. J. Exp. Med. 155:1523-2536.

20. Howard, M., and W. E. Paul. 1983. Regulation of B cell growth and differentiation by soluble factors. Ann. Rev. Immunol. 1:307-333.
21. Dixon, F. J. 1982. Murine lupus-an overview. Arthritis Rheum. 25:721-725.

22. Aldo-Benson, M. A., and Y. Borel. 1977. Hapten bearing cell in carrier determined tolerance. Eur. J. Immunol. 7:175-179.

23. Nosal, G. J. V. 1983. Cellular mechanisms of immunologic tolerance. Ann. Rev. Immunol. 1:33-62.

24. Aldo-Benson, M. A. 1985. The signal for tolerance in B cells is not transmitted through antigen-specific immunoglobulin receptors. Fed Proc. 44:2493-2496.

25. Lewis, R. M., C. A. Smith, L. Kilham, and Y. Borel. 1979. Sex differences in the maintenance of immunologic tolerance to endogenous nucleic acid antigens and the prevention of murine lupus nephritis. Clin. Immunol. Immunopathol. 13:92-102. 